\title{
Effect of Ge autodoping during III-V MOVPE growth on Ge substrates
}

\author{
Laura Barrutia*, Enrique Barrigón ${ }^{+}$, Iván García, Ignacio Rey-Stolle and \\ Carlos Algora \\ Instituto de Energía Solar, Universidad Politécnica de Madrid, Avda. Complutense 30, \\ 28040 Madrid, Spain \\ ${ }^{+}$Present address: Solid State Physics, Department of Physics and NanoLund, \\ Lund University, Box 118, 22100 Lund, Sweden
}

\begin{abstract}
During the MOVPE growth of III-V layers on Ge substrates, Ge atoms can be evaporated or etched from the back of the wafer and reach the growth surface, becoming incorporated into the epilayers. This is the so-called Ge autodoping effect, which we have studied through a set of growth experiments of GaInP and $\mathrm{Ga}(\mathrm{In}) \mathrm{As}$ layers lattice matched to Ge substrates, which have been characterized by Secondary Ion Mass Spectroscopy. The role of V/III ratio and growth rate on Ge autodoping has been studied and a MOVPE reactor pre-conditioning prior to the epitaxial growth of III-V semiconductor layers that mitigates this Ge autodoping has been identified. In addition, the use of 2-inch versus 4-inch Ge substrates has been compared and the use of a $\mathrm{Si}_{3} \mathrm{~N}_{4}$ backside coating for the Ge substrates has been evaluated.
\end{abstract}

Keywords: III-V semiconductor, Ge autodoping, GaInP solar cells, multijunction solar cell

* Corresponding author. E-mail address laura.barrutia@ies-def.upm. (L. Barrutia) 


\section{INTRODUCTION}

Germanium wafers are widely used in MOVPE as the substrate of choice for triple junction solar cells, for both space and terrestrial applications, and some LEDs. Germanium has a lattice constant quite close to that of GaAs and offers some advantages over GaAs substrates such as lower cost, higher mechanical strength, very low dislocation density and a slightly higher thermal conductivity. In the particular field of multijunction solar cells, which represents in excess of $80 \%$ of the world market for Ge substrates, Germanium has been shown to be an excellent candidate material as the bottom cell (BC) [1]. This is because of Ge shows an adequate energy bandgap ( $\left.\mathrm{E}_{\mathrm{g}} \sim 0.66 \mathrm{eV}\right)$, it can be employed as the mechanical support of the stack (as a result of the aforementioned mechanical and thermal properties) and it is compatible with the subsequent growth of a vast collection of III-V compound semiconductors (i.e., other subcells can be grown on top). In fact, 3-junction solar cells grown on a Ge substrate, which acts as an active junction, are nowadays the most mature and commercially exploited architecture of multijunction solar cells for space and terrestrial applications.

However, the use of Ge as the substrate for III-V based multijunction solar cells (MJSC) imposes extra challenges regarding the epitaxial growth in comparison to MJSCs grown on GaAs or InP substrates. First, since Ge presents a non-polar structure, a heteroepitaxial routine is required to grow defect-free polar III-V layers on the Ge substrate. This can be accomplished by the use of a misoriented Ge substrate [2], together with a dedicated surface preparation prior growth $[3,4,5,6]$. Secondly, the cross-diffusion that takes place during the epitaxial growth must be controlled. On the one hand, group-III and V elements are dopants in Ge. This is of key relevance when the Ge wafer is intended to act as a solar cell (as is the case of $\mathrm{GaInP} / \mathrm{Ga}(\mathrm{In}) \mathrm{As} / \mathrm{Ge}$ triple junction solar cells) since the diffusion of these elements determines the configuration of the resulting $\mathrm{Ge} p / \mathrm{n}$ junction and thus rules the solar cell performance $[7,8]$. On the other hand, Ge is in turn a dopant in III-V semiconductors $[9,10,11]$, which can be incorporated into the III-V epilayers by diffusion during the epitaxial growth. We will refer to the latter process as solid-phase Ge diffusion. 
In addition to solid-phase diffusion, which is a phenomenon limited to the vicinity of the III-V/Ge interface $(\sim 150 \mathrm{~nm})$, there is another source of Ge contamination than can affect all III-V layers throughout the growth, namely, Ge autodoping. Ge autodoping refers to the process by which Ge atoms leave the substrate, reach the gas phase and can be subsequently incorporated into the III-V epilayers during the MOVPE growth. Ge autodoping can be direct when it originates from Ge atoms that either evaporate from the substrate or are chemically etched away from the rear side of the wafer by $\mathrm{H}_{2}$ [12], $\mathrm{AsH}_{3}$ or $\mathrm{PH}_{3}$ flows [6]. Last but not least, Ge autodoping can be indirect when it stems from Ge atoms that are re-evaporated from the chamber walls due to reactor history. Even though special MOVPE routines have been developed to control the solid-phase diffusion of group-III and $\mathrm{V}$ elements on Ge and vice versa for III-V based MJSC $[13,14,15]$, little attention has been paid to Ge autodoping [16, 17]. Accordingly, in this paper we present a comprehensive study of Ge autodoping on $\mathrm{Ga}_{0.99} \mathrm{In}_{0.01} \mathrm{As}$ and $\mathrm{Ga}_{0.51} \mathrm{In}_{0.49} \mathrm{P}$-hereinafter simply noted as $\mathrm{Ga}(\mathrm{In}) \mathrm{As}$ and $\mathrm{GaInP}$, respectively-grown by MOVPE, since these two are the most common materials used in state-of-the art triple junction solar cells. In particular, the effect of V/III ratio, growth rate, growth temperature, reactor pre-conditioning and size of Ge substrate will be assessed. We also show the beneficial effect of using a $\mathrm{Si}_{3} \mathrm{~N}_{4}$ backside coating on the wafers to reduce Ge autodoping.

\section{EXPERIMENTAL}

Epiwafers were grown by MOVPE in a horizontal, low pressure, AIX200/4 reactor. Before growth, our standard Ge substrate surface preparation was carried out with the help of in-situ monitoring by using Reflectance Anisotropy Spectroscopy (RAS) [4,18]. Trimethylgallium (TMGa), Trimethylindium (TMIn) were used as the group-III precursors and $\mathrm{PH}_{3}$ and $\mathrm{AsH}_{3}$ as the group-V precursors. III-V layers were grown on (100) Ge substrates with a miscut of $6^{\circ}$ towards the nearest (111) plane, doped with gallium (p-type). The substrates used included 2-inch wafers (150 $\mu \mathrm{m}$ thick); 
4-inch wafers (175 $\mu$ m thick) and 4-inch wafers with their backside coated with a $100 \mathrm{~nm}$ thick $\mathrm{Si}_{3} \mathrm{~N}_{4}$ layer.

Figure 1, shows the basic semiconductor structure employed for this study. It consists of a set of alternating GaInP and $\mathrm{Ga}(\mathrm{In}) \mathrm{As}$ layer pairs grown lattice matched to the Ge substrate. Growth parameters such as V/III ratio, temperature and growth rate used for each $\mathrm{GaInP} / \mathrm{Ga}(\mathrm{In}) \mathrm{As}$ layer pairs will be later indicated for each dedicated experiment. Layers were grown nominally undoped so any Ge content should come from either solid-phase diffusion or autodoping. To account for possible runto-run temperature variations, the wafer surface temperature was monitored in situ for each growth by using pyrometry with an EpiTT tool from Laytec. Along this paper we will include both the nominal target temperature for each experiment ( $\left.\mathrm{T}_{\text {nominal }}\right)$, which corresponds to the reading of the thermocouple embedded into the susceptor holding the wafer, as well as the value obtained by pyrometry $\left(\mathrm{T}_{\text {pyrometry }}\right)$.

Secondary Ion Mass Spectroscopy (SIMS) was used to determine the amount of Ge incorporated along the layers. Cesium $\left(\mathrm{Cs}^{+}\right)$was used as the primary ions source. A medium mass resolution was used in order to separate germanium isotopes from possible Ga or As based mass interfering species. The quantification of germanium concentration was performed using GaInP and $\mathrm{Ga}(\mathrm{In}) \mathrm{As}$ germanium implanted standards which were measured as references together with the rest of the samples. Gallium $(\mathrm{Ga})$ and indium (In) were not quantified on these samples and were given in counts/s, since they were measured just to identify the boundaries of the different layers of the sample. For these measurements, a high impact energy and sputtering rate were used in order to analyze the required depth ( 1 to $2 \mu \mathrm{m})$ and to have a low detection limit for Ge. In this case, ion mixing effect is more important and depth resolution is reduced leading to more rounded interfaces. The description of the typical SIMS profile achieved will be presented in section III-B. For the SIMS analysis, in most cases layer thicknesses of $\sim 300 \mathrm{~nm}$ were grown. In some runs, thinner layers of around $100 \mathrm{~nm}$ were used for the $\mathrm{Ga}(\mathrm{In})$ As layers. Anyhow, in all cases it was checked that layers were thick enough to 
obtain a plateau free of boundary effects where the intensity of the autodoping could be assessed. Moreover, in order to avoid these interface effects, Ge concentration in each layer is calculated as the average of the concentrations obtained from the SIMS measurements only at the central part of each layer. Correspondingly, the uncertainty in the concentration value has been assumed to be equal to the standard deviation.

\begin{tabular}{|c|c|}
\hline $\mathrm{Ga}(\ln ) \mathrm{As}$ & $\sim 300 \mathrm{~nm}$ \\
\hline GalnP & $\sim 300 \mathrm{~nm}$ \\
\hline $\mathrm{Ga}(\operatorname{In}) \mathrm{As}$ & $\sim 300 \mathrm{~nm}$ \\
\hline GalnP & $\sim 300 \mathrm{~nm}$ \\
\hline $\mathrm{Ga}(\operatorname{In}) \mathrm{As}$ & $\sim 300 \mathrm{~nm}$ \\
\hline GalnP & $\sim 300 \mathrm{~nm}$ \\
\hline \multicolumn{2}{|c|}{ Substrate $\mathrm{p}^{++} \mathrm{Ge}$} \\
\hline
\end{tabular}

Figure 1. Schematic of the structures grown on Ge for this study, consisting of three pairs of alternating $\mathrm{GaInP} / \mathrm{Ga}(\mathrm{In}) \mathrm{As}$ epilayers. Depending on the experiment, different temperatures have been used for the different pairs of layers. Details on the temperatures used $\left(T_{1}, T_{2}\right.$ and $\left.T_{3}\right)$ will be indicated in the section describing each experiment.

\section{RESULTS AND DISCUSSION}

\section{A. Influence of the growth rate and V/III ratio}

In order to ascertain the influence of V/III ratio and growth rate on the incorporation of Ge for both GaInP and $\mathrm{Ga}(\mathrm{In}) \mathrm{As}$ layers, a set of experiments varying these parameters were performed. The structure grown was that shown on Figure 1 and the growth temperature was set to a nominal value of $675^{\circ} \mathrm{C}\left(\mathrm{T}_{\text {pyrometry }} \sim 620^{\circ} \mathrm{C}\right)$ for all the layers $\left(\mathrm{T}_{1}=\mathrm{T}_{2}=\mathrm{T}_{3}=675^{\circ} \mathrm{C}\right)$. 

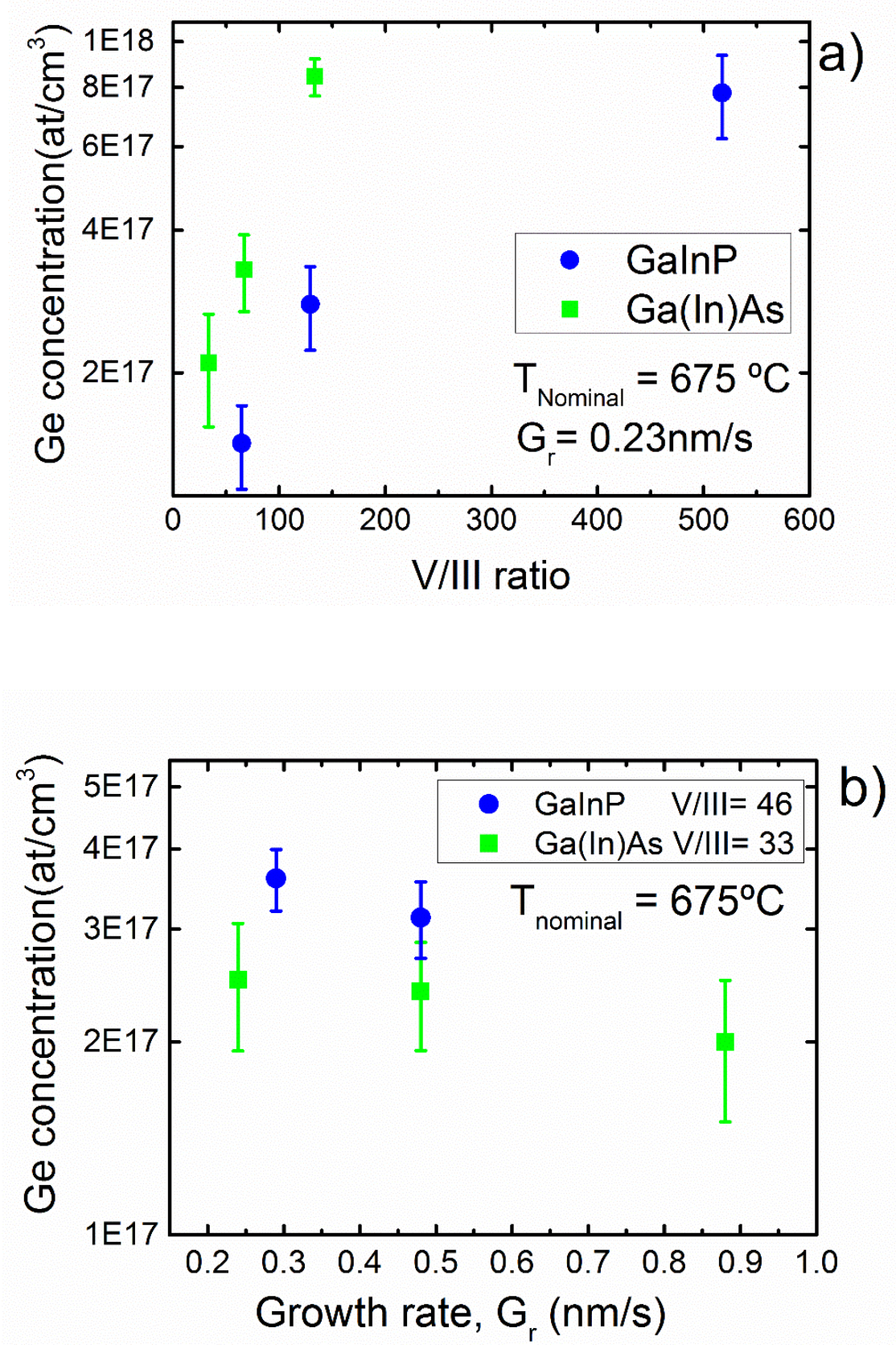

Figure 2. SIMS results of the Ge concentration $\left(\mathrm{at} / \mathrm{cm}^{3}\right)$ incorporated in both $\mathrm{Ga}(\mathrm{In}) \mathrm{As}$ and $\mathrm{GaInP}$ layers as function of the (a) V/III ratio for a constant growth rate of $\sim 0.23 \mathrm{~nm} / \mathrm{s}$ and (b) growth rate for a constant V/III ratio of 46 for the GaInP and 33 for the Ga(In)As. The extension of the error bars accounts for the standard deviation of the mean value. 
To analyze the impact of the V/III ratio, the partial pressure of the group-V precursor was varied while the partial pressures of the group-III precursors were kept constant yielding a growth rate of $0.23 \mathrm{~nm} / \mathrm{s}( \pm 10 \%)$. Three pairs of $\mathrm{GaInP} / \mathrm{Ga}(\mathrm{In})$ As layers were grown, with increasing V/III ratios for each pair. Figure 2.a represents the evolution of $\mathrm{Ge}$ concentration in $\mathrm{Ga}(\mathrm{In}) \mathrm{As}$ and $\mathrm{GaInP}$ as a function of V/III ratio. As can be seen in Figure 2.a, the higher the V/III ratio the higher the Ge concentration. In addition, Ge incorporation is higher for $\mathrm{Ga}(\mathrm{In}) \mathrm{As}$ than for GaInP layers (a factor 2 and 3 for V/III ratios of $\sim 65$ and $\sim 130$, respectively). The mechanism behind this difference could be the faster Ge wafer etching when $\mathrm{AsH}_{3}$ is used instead of $\mathrm{PH}_{3}[19,20]$. This different etching provides a higher partial pressure of Ge during the growth of $\mathrm{Ga}(\mathrm{In})$ As layers which results in a higher Ge incorporation in these layers. Finally, in order to discard the possibility that the results of Figure 2.a were affected by the order in which layers were grown (i.e. steady increase of V/III ratios) an additional set of samples was grown in which the structure of Figure 1 was capped with a final pair of GaInP/GaInAs layers repeating the same conditions as in the first pair (low V/III 65). The corresponding SIMS analyses (not shown here) have provided essentially the same Ge incorporation (considering the measurement uncertainties), ruling out any significant influence from the order in which the experiments were performed. In addition, we included a couple of control samples with repeated experiments grown in different order to check the run-to-run reproducibility, which was again confirmed to be within the uncertainty of the SIMS measurements.

A similar procedure was followed to assess the influence of the growth rate. For this purpose, the partial pressures of the group-III precursors were increased for each pair of layers achieving growth rates of around $0.2,0.5$ to $0.9 \mathrm{~nm} / \mathrm{s}$ in the different pairs. To maintain the V/III ratio constant (at values of 46 for $\mathrm{GaInP}$ and 33 for $\mathrm{Ga}(\mathrm{In}) \mathrm{As}$ ), the partial pressure of group-V precursor was varied accordingly. Figure 2.b shows the evolution of the Ge concentration in $\mathrm{Ga}(\mathrm{In}) \mathrm{As}$ and GaInP as a function of the growth rate. As it can be observed in Figure 2.b, as the growth rate increases the Ge concentration remains almost constant or even decreases slightly. However, this cannot be fully 
clarified as a result of the magnitude of the uncertainty in the measurements. Anyhow, what is evident is that the effect of the growth rate (while keeping the V/III constant) on the Ge autodoping is not as strong as the V/III ratio influence. This behavior can be explained considering the fact that the incorporation of the dopants is proportional to the dopant partial pressure and inversely proportional to the partial pressure of the species competing for the same sublattice site [21]. Since Ge has been found to be an n-type dopant for both GaInP and $\mathrm{Ga}(\mathrm{In}) \mathrm{As}$, its incorporation competes with that of group-III elements ( $\mathrm{Ga}$ and $\mathrm{In}$ ). In addition, as it was already mentioned, in order to maintain a constant V/III ratio in this experiement, the group-V partial pressure was scaled as much as those of group-III to reach a certain growth rate. Therefore, as growth rate is increased so is group-V partial pressure and thus so should be the release of Ge atoms from the substrate as a result of etching. However, this increase in Ge avalability is counterbalanced by a proportional increase of group-III atoms competing for the same sublattice sites. The effects of these competing phenomena appear to cancel out, and almost no impact of the growth rate at a constant V/III ratio on the Ge concentration is observed in Figure 2.b.

Finally, it should be noted that we do not observe any deposits on the rear side of the Ge substrate either when growing GaInP or $\mathrm{Ga}(\mathrm{In}) \mathrm{As}$. In this respect, we can consider that the rear side of the substrate is acting as a semi-infinite source of Ge atoms and therefore, no depletion of Ge should occur along the epitaxial process.

\section{B. Influence of the growth temperature and reactor preconditioning}

According to Figure 2, etching of the Ge substrate by the hydrides involved in the MOVPE process is key for Ge autodoping. Growth temperature may increase the etching rate, which will in turn enhance Ge autodoping. Despite the fact that the MOVPE reactor has never been used to grow Ge, the reactor pre-conditioning (reactor history, preexisting reactor coatings...) might play an important role in gettering some Ge. Since etching will mostly occur at the perimeter and the backside of the Ge substrate, the ability of etched Ge atoms to reach the growing surface will strongly depend on 
what environment they encounter in their trip to the front side (coatings on the substrate and /or the substrate susceptor, substrate size, etc.). In order to shed some light on these effects, we have done a study of Ge autodoping for three different reactor conditions at three different growth temperatures for both $\mathrm{GaInP}$ and $\mathrm{Ga}(\mathrm{In})$ As layers without any intentional doping. In this section, for each reactor pre-condition (to be described later) each pair of $\mathrm{GaInP}$ and $\mathrm{Ga}(\mathrm{In}) \mathrm{As}$ layers of Figure 1 were grown at different temperatures, namely starting with the higher temperatures and going down to minimize Ge solid-phase diffusion $\left(\mathrm{T}_{1}=675^{\circ} \mathrm{C}, \mathrm{T}_{2}=600{ }^{\circ} \mathrm{C}\right.$ and $\left.\mathrm{T}_{3}=550{ }^{\circ} \mathrm{C}\right)$. In this experiment, GaInP and $\mathrm{Ga}(\mathrm{In}) \mathrm{As}$ were grown at growth rates of 0.21 and $0.65 \mathrm{~nm} / \mathrm{s}$ and V/III ratios of 410 and 16 , respectively. These conditions were chosen since they allow us to obtain layers with minimum roughness and defect density in our MOVPE reactor. Therefore, these conditions are interesting to maintain good morphologies along the growth of very complex structures (such as multijunction solar cells or LEDs) but, as demonstrated in the previous section, do not necessarily lead to the minimization of Ge autodoping effects (particularly in the case of GaInP).

Table 1. Schematics of the three reactor pre-conditions used in the growths.

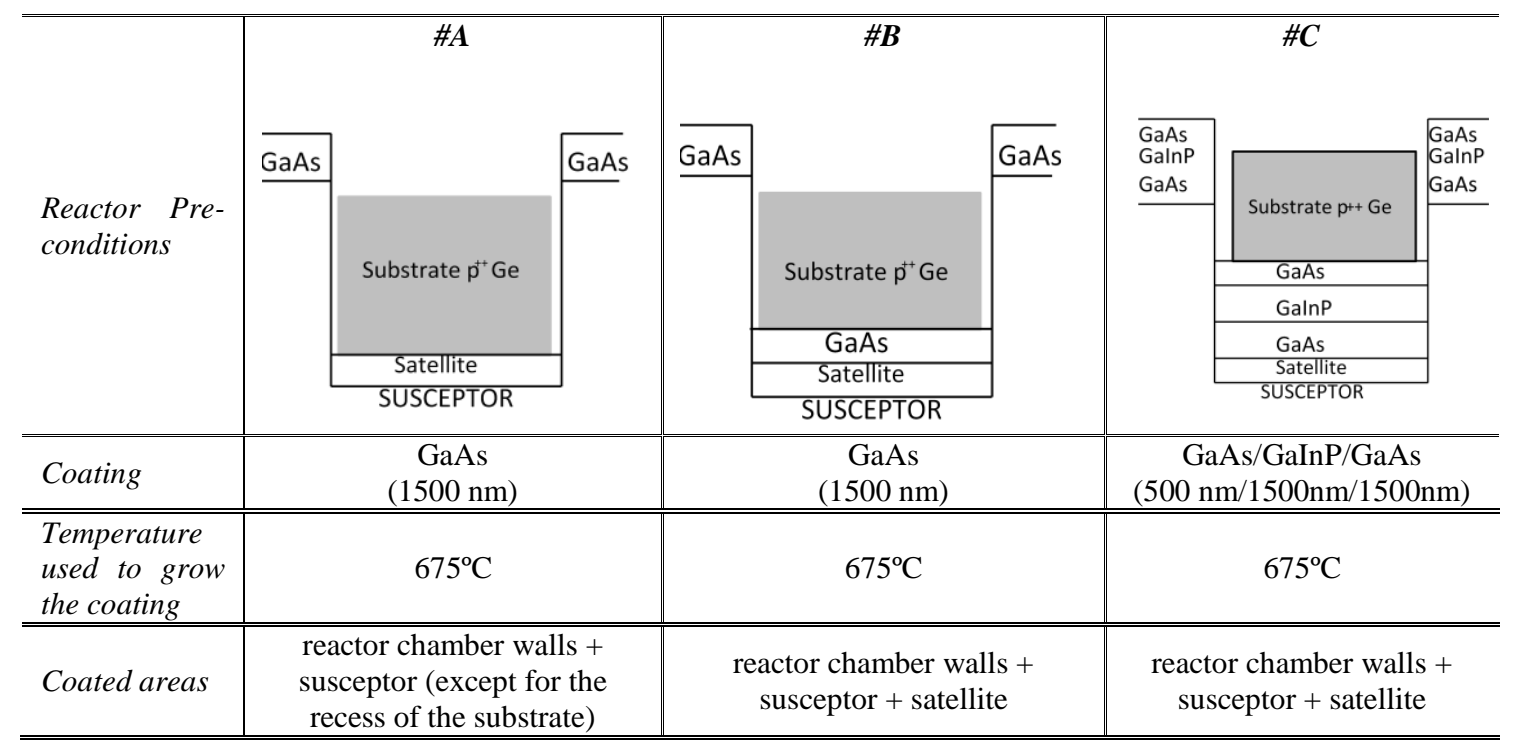

The three different reactor pre-conditionings used are briefly summarized in Table 1. With precondition \#A, a GaAs coating was deposited on the chamber except for the recess in which the 
substrate sits during the growth (i.e. the back side of the Ge substrate is directly in contact with the graphite of the susceptor). In reactor pre-condition $\# \mathrm{~B}$, the same coating was done but covering the whole chamber (i.e. the back side of the Ge substrate is directly in contact with the GaAs coating on the susceptor). Finally, in reactor pre-condition \#C, a more complex coating consisting of GaAs (500nm) followed by thicker GaInP and GaAs layers ( 1.5 $\mu$ m each) was done on the whole chamber.

After the epitaxial growth, epiwafers were characterized by SIMS whose profiles are shown in Figure 3, where a different color is used for each reactor pre-condition (green, red and black). As it can be observed, the growth temperature plays an important role when Ge autodoping is to be controlled. From right to left in Figure 3.a, four regions can be observed as labeled in the figure. The first region, labelled as (1), consists of an abrupt or steep interface of $\sim 25 \mathrm{~nm}$ where the Ge concentration decreases from that of bulk Ge to $5 \cdot 10^{18} \mathrm{~cm}^{-3}$; region (2) follows a tail-like profile, where Ge concentration decreases from $4 \cdot 10^{18}$ to $\sim 3 \cdot 10^{17} \mathrm{at} / \mathrm{cm}^{3}$. Regions (1) and (2) constitute the expected kink and tail profile for the solid-phase diffusion of Ge from the substrate into the first-grown GaInP epilayer [17]. Region (3) is attributed to vapor phase autodoping, since the Ge concentration is relatively flat for all the three temperatures. Similar SIMS profiles have been shown in $[22,17]$ when growing $\mathrm{Ga}(\mathrm{In}) \mathrm{As}$ or GaInP on Ge substrates at $650^{\circ} \mathrm{C}$ and $630^{\circ} \mathrm{C}$, respectively. The right part of Figure 3 shows a zoomin of the profiles associated to $\mathrm{Ge}$ autodoping for $\mathrm{GaInP}$ and $\mathrm{Ga}(\mathrm{In}) \mathrm{As}$ grown at $675^{\circ} \mathrm{C}$, namely, region (3). For the case of reactor pre-condition \#C (black line) where a thicker and more complex coating of $\mathrm{GaAs} / \mathrm{GaInP} / \mathrm{GaAs}$ was done prior to growth, it was found that the Ge concentration in the layers was a factor $\sim 2.5$ lower $\left(9.7 \cdot 10^{16}\right.$ atoms $\left./ \mathrm{cm}^{3}\right)$ than in the other two cases. At this point, it is difficult to ascribe the better performance of coating \#C to the increase in thickness or to its including a thick GaInP layer. Anyhow, we speculate that the reason for this reduction is that the thick GaAs and/or GaInP layers in this coating act as efficient gettering centers for part of the Ge atoms escaping from the substrate as well as block the escape of possible Ge contamination from the susceptor. For the two other reactor pre-conditions \#A and \#B, the Ge concentration was not reduced significantly and 
it was virtually the same for both $\left(\sim 2.5 \cdot 10^{17}\right.$ atoms $\left./ \mathrm{cm}^{3}\right)$. Regarding the $\mathrm{Ga}(\mathrm{In})$ As layer grown at $675^{\circ} \mathrm{C}$, a lower Ge doping level than in GaInP grown at the same T was achieved for the three different reactor pre-conditionings $\left(\sim 4 \cdot 10^{16}\right.$ atoms $/ \mathrm{cm}^{3}$ for reactor pre-conditions \#C while $\sim 7 \cdot 10^{16}$ for the other two pre-conditions) which can be attributed to the lower V/III ratio used to grow the Ga(In)As, as shown in section III.A. Following the SIMS analysis in Figure 3, it can be seen that Ge concentration further decreases when temperature goes down from $675^{\circ} \mathrm{C}$ to $600^{\circ} \mathrm{C}$ and then to $550^{\circ} \mathrm{C}$ (region 4), reaching a value $\sim 4 \cdot 10^{16}$ atoms $/ \mathrm{cm}^{3}$. However, although it has been demonstrated that lower temperatures help reduce the amount of Ge atoms that are incorporated via gas phase transport [12]. Figure 3 shows the stagnant value of $4 \cdot 10^{16} \mathrm{atoms} / \mathrm{cm}^{3}$. This is because this level represents the SIMS detection limit for Ge in our measurement, so this value should be considered as an upper bound for Ge concentration in these layers and not an accurate determination of the real Ge concentration in them. Anyhow, background doping values in this range can be tolerated in LED and solar cell applications.
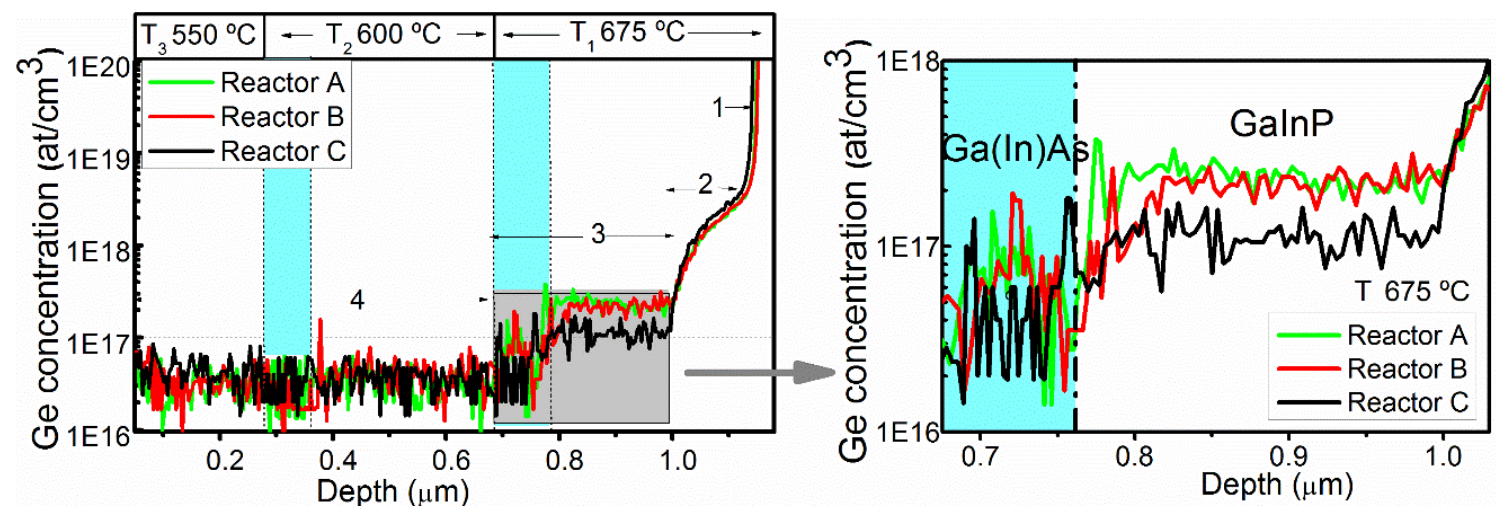

Figure 3. (Left) Ge concentration quantified by SIMS in the III-V layers of the structure of Figure 1. For these particular experiments, the thickness of the $\mathrm{Ga}(\mathrm{In})$ As layers was reduced to $\sim 100 \mathrm{~nm}$ (shaded blue areas). For each reactor pre-condition (A, B and C) the layers were grown at three different nominal temperatures of $675^{\circ} \mathrm{C}\left(\mathrm{T}_{\text {pyrometry }} \sim 620^{\circ} \mathrm{C}\right), 600^{\circ} \mathrm{C}\left(\mathrm{T}_{\text {pyrometry }} \sim 575^{\circ} \mathrm{C}\right)$ and $550^{\circ} \mathrm{C}$ $\left(\mathrm{T}_{\text {pyrometry }} \sim 530^{\circ} \mathrm{C}\right)$. (Right) Magnification of the area shaded in gray (region 3 ) where the main influence of each reactor pre-condition is observed. 
From this batch of experiments performed on 2-inch Ge substrates, we can conclude that: 1) at the III-V/Ge interface, Ge solid-phase diffusion dominates and extends for $\sim 150 \mathrm{~nm}$ into the III-V layers; 2) different reactor pre-conditionings have an impact on Ge autodoping, in particular, thicker susceptor coatings (in our experiment including both GaAs and GaInP layers) show a clear Ge gettering/blocking effect decreasing the incorporation of Ge into the epilayers; and 3) at nominal growth temperatures lower than $600^{\circ} \mathrm{C}$ the Ge concentration is equal to or lower than our SIMS detection limit $\left(\sim 4 \cdot 10^{16}\right.$ atoms $\left./ \mathrm{cm}^{3}\right)$ which is low enough for most solar cell and LED applications.

\section{Ge substrate size: 4-inch versus 2-inch.}

In order to assess the influence of the substrate size, similar experiments as those of section III.B were performed on 4-inch Ge substrates. In this case, only reactor pre-condition \#C was used (i.e. wafer backside in contact with a GaAs/GaInP coating on the graphite susceptor). The experiment consisted again in the growth of the structure depicted in Figure 1 following the same recipe as for the 2-inch substrates discussed in the previous section III.B while ensuring that the substrate surface temperature was the same despite the change in substrate size.

Table 2 compares the Ge autodoping, as measured by SIMS, in points at the center of each wafer, in GaInP and $\mathrm{Ga}(\mathrm{In}) \mathrm{As}$ layers grown at $675^{\circ} \mathrm{C}$ on 4 -inch and 2-inch substrates. As this Table shows, when using 4-inch Ge substrates, no change is observed in Ge incorporation for Ga(In)As, which still remains at our lower detection limit. This is consistent with the low V/III ratio ( 16) used to grow this layer. However, there is a significantly higher Ge concentration in GaInP -which is grown at a significantly higher V/III ratio (>400)-, with an increase of a factor of $\sim 6$ as compared with the 2inch substrates. This suggests that the availability of Ge atoms to contribute to autodoping is greatly affected by the increase in the substrate size, this being a strong proof that Ge autodoping is mainly an area driven phenomenon rather than a perimeter driven phenomenon. However, the increase in surface from 2-inch to 4-inch wafers only accounts for a factor of 4, whereas Table 2 shows a 6-fold increase in Ge concentration. Accordingly, other factors should also play an influence. In this respect, 
we believe that the greater bowing that 4 -inch wafers experiment -as compared with 2 -inch- would allow a more efficient release of Ge atoms from the backside to the growing surface at the front of the wafer. Also as a result of bowing, it is possible that the gettering effect of the susceptor coating on these larger wafers is less effective. However, the latter should be considered just a speculation since we did not reproduce this experiment with reactor pre-conditions \#A and \#B.

Table 2: Ge average concentration values as measured by SIMS at the center of each wafer for GaInP and $\mathrm{Ga}(\mathrm{In})$ As layers grown on 2 and 4 -inch Ge substrates. Growth conditions were as follows: 1) for $\mathrm{GaInP} ; \mathrm{G}_{\mathrm{r}}=0.21 \mathrm{~nm} / \mathrm{s}$ and V/III $>400 ; 2$ ) for $\mathrm{Ga}(\mathrm{In}) \mathrm{As} ; \mathrm{G}_{\mathrm{r}}=0.65 \mathrm{~nm} / \mathrm{s}$ and V/III=16.

\begin{tabular}{c|c|c}
\hline Layer & 2 inch-Ge wafer & 4-inch-Ge wafer \\
\hline \hline GaInP & $9.710^{16} \pm 34 \%$ & $6.610^{17} \pm 22 \%$ \\
\hline \hline$G a(\operatorname{In}) A s$ & $<310^{16} \pm 12 \%$ & $<310^{16} \pm 19 \%$ \\
\hline
\end{tabular}

As the conditions we use to grow GaInP make it more sensitive to Ge autodoping, in the following we will focus just on GaInP.

\section{Influence of a $\mathrm{Si}_{3} \mathrm{~N}_{4}$ backside coating of the Ge substrate.}

With the aim of reducing the high Ge autodoping effect found for GaInP layers grown on 4-inch substrates, Ge substrates with a $\mathrm{Si}_{3} \mathrm{~N}_{4}$ layer coating on the backside were used [23]. By performing the same batch of experiments on Ge substrates with and without $\mathrm{Si}_{3} \mathrm{~N}_{4}$ followed by identical SIMS analysis at the center of the wafer, it can be observed how this back coating layer actually helps to reduce the amount of Ge atoms being evaporated/etched from the substrate and thus reduces the Ge concentration in the GaInP layers. Table 3 shows a brief summary of the SIMS results comparing the Ge doping of GaInP layers grown at three different temperatures on 4-inch substrates with and without $\mathrm{Si}_{3} \mathrm{~N}_{4}$. As this table shows, for nominal temperatures of $700^{\circ} \mathrm{C}$ and $650^{\circ} \mathrm{C}$, a reduction by a 
factor $\sim 3$ was obtained. Please note that for these particular experiments, a second batch of SIMS measurements was carried out for which the SIMS detection limit for the GaInP layers was reduced down to concentration levels of $1.5 \cdot 10^{16} \mathrm{~cm}^{-3}$.

Table 3. Ge concentration from autodoping as measured by SIMS for GaInP epilayers grown at different nominal temperatures of $700^{\circ} \mathrm{C}\left(\mathrm{T}_{\text {pyrometry }} \sim 650^{\circ} \mathrm{C}\right), 650^{\circ} \mathrm{C}\left(\mathrm{T}_{\text {pyrometry }} \sim 610^{\circ} \mathrm{C}\right)$ and $615^{\circ} \mathrm{C}$ $\left(\mathrm{T}_{\text {pyrometry }} \sim 585^{\circ} \mathrm{C}\right)$ on 4 -inch $\mathrm{Ge}$ substrates with and without $\mathrm{Si}_{3} \mathrm{~N}_{4}$ backside coating. Growth conditions were $\mathrm{G}_{\mathrm{r}}=0.21 \mathrm{~nm} / \mathrm{s}$ and $\mathrm{V} / \mathrm{III}>400$.

\begin{tabular}{l|c|c|c}
\hline \hline Growth Temperature & $700^{\circ} \mathrm{C}$ & $650^{\circ} \mathrm{C}$ & $615^{\circ} \mathrm{C}$ \\
\hline $\begin{array}{l}\text { Ge concentration }\left(\mathrm{cm}^{-3}\right) \\
\text { without } \mathrm{Si}_{3} \mathrm{~N}_{4} \text { coating }\end{array}$ & $1.210^{18} \pm 6 \%$ & $1.110^{17} \pm 23 \%$ & $1.510^{16} \pm 60 \%$ \\
\hline $\begin{array}{l}\text { Ge concentration }\left(\mathrm{cm}^{-3}\right) \\
\text { with } \mathrm{Si}_{3} \mathrm{~N}_{4} \text { coating }\end{array}$ & $4.010^{17} \pm 11 \%$ & $3.810^{16} \pm 33 \%$ & $\leq 1.510^{16} \pm 55 \%$ \\
\hline \hline
\end{tabular}

\section{E. Difference between substrate center and perimeter.}

Finally, Ge SIMS profiles were measured at the center and at the edge of 4-inch Ge substrates (with and without $\mathrm{Si}_{3} \mathrm{~N}_{4}$ back coatings) as shown in Table 4 . As it can be observed, the gas phase autodoping is more severe at the edge than at the center for all temperatures and for both coated and bare wafers. This is so even despite the fact that the edge of the epiwafer should be slightly cooler that the center -as a result of wafer bowing in 4-inch substrates-, because the edge of the epiwafer is exposed to larger quantities of evaporated Ge as it is closer to the rear side. Therefore, as germanium is mainly incorporated at the edge its concentration in the gas phase radially decreases towards the center of the epiwafer. Table 4, shows that the $\mathrm{Si}_{3} \mathrm{~N}_{4}$ layer actually helps to reduce this Ge autodoping. For a growth temperature of $650^{\circ} \mathrm{C}$ on $\mathrm{Si}_{3} \mathrm{~N}_{4}$ coated wafers, both the edge and the center of the wafer show $\mathrm{Ge}$ concentrations resulting from autodoping in the mid-range of $10^{16} \mathrm{~cm}^{-3}$ (a value which is acceptable 
for most LED and solar cell applications). Obviously, Ge autodoping increases notably with temperature and, at $700^{\circ} \mathrm{C}$, values are unbearably high for both coated and uncoated wafers (especially at the perimeter). This can be explained by the fact that the number of Ge atoms evaporated and/or chemically etched at the back surface of the substrate will probably show an Arrhenius-like dependence with temperature, together with the assumption that bowing will increase with temperature thus allowing a more efficient transport of Ge atoms from below the substrate.

Table 4. Ge concentration from autodoping as measured by SIMS in GaInP layers at the center and at the perimeter of the epiwafer. The layers were grown at two different nominal temperatures of $700^{\circ} \mathrm{C}\left(\mathrm{T}_{\text {pyrometry }} \sim 650^{\circ} \mathrm{C}\right)$ and $650^{\circ} \mathrm{C}\left(\mathrm{T}_{\text {pyrometry }} \sim 610^{\circ} \mathrm{C}\right)$ on 4-inch Ge substrates with and without $\mathrm{Si}_{3} \mathrm{~N}_{4}$ backside coating.

\begin{tabular}{l|c|c||c}
\hline \hline & Growth $T\left({ }^{\circ} \mathrm{C}\right)$ & $700^{\circ} \mathrm{C}$ & $650^{\circ} \mathrm{C}$ \\
\hline \hline \multirow{2}{*}{$\begin{array}{l}\text { Ge concentration }\left(\text { atoms } / \mathrm{cm}^{3}\right) \text { in wafers } \\
\text { without } \mathrm{Si}_{3} \mathrm{~N}_{4} \text { coating }\end{array}$} & Center & $1.210^{18} \pm 6 \%$ & $1.110^{17} \pm 23 \%$ \\
\cline { 2 - 4 } & Perimeter & $7.610^{18} \pm 11 \%$ & $6.910^{17} \pm 12 \%$ \\
\hline $\begin{array}{l}\text { Ge concentration }\left(\text { atoms } / \mathrm{cm}^{3}\right) \text { in wafers } \\
\text { with } \mathrm{Si}_{3} \mathrm{~N}_{4} \text { coating }\end{array}$ & Center & $4.010^{17} \pm 11 \%$ & $3.810^{16} \pm 33 \%$ \\
\cline { 2 - 4 } & Perimeter & $2.010^{18} \pm 5 \%$ & $6.410^{16} \pm 37 \%$ \\
\hline
\end{tabular}

\section{CONCLUSIONS}

Ge autodoping plays an important role when growing GaInP and $\mathrm{Ga}(\mathrm{In}) \mathrm{As}$ III-V semiconductors on Ge substrates by MOVPE. Growing parameters such as temperature and V/III ratio directly influence the incorporation of Ge into $\mathrm{GaInP}$ and $\mathrm{Ga}(\mathrm{In}) \mathrm{As}$ layers grown on Ge wafers. In general, higher temperatures and higher V/III ratios produce higher Ge incorporation levels while the growth rate (while keeping the V/III constant) does not seem to have a major impact on Ge incorporation. $\mathrm{Ga}(\mathrm{In})$ As seems to be more affected than GaInP by Ge autodoping, which could be attributed to a higher partial pressure of Ge present in the gas phase as a result of a more severe Ge substrate etching when $\mathrm{AsH}_{3}$ is used (instead of $\mathrm{PH}_{3}$ ) as the group-V precursor. Moreover, Ge autodoping is also affected by the MOVPE reactor pre-conditioning. In this sense, different coatings on the reaction 
chamber have shown to have a large impact on Ge autodoping for 2-inch substrates and Ge incorporation can be minimized by coating the susceptor on which the wafer sits with $\mathrm{Ga}(\mathrm{In}) \mathrm{As}$ and GaInP layers to block and getter the Ge atoms. In addition, the impact of both the substrate size and radial dependence of Ge doping concentration in the epiwafer has been analyzed. In this respect, Ge autodoping has been found to be more severe in larger wafers, suggesting a mainly area-driven phenomenon. Finally, in all cases it has been shown that coating the backside of the Ge substrates with $\mathrm{Si}_{3} \mathrm{~N}_{4}$ is an efficient way to minimize the effects of $\mathrm{Ge}$ autodoping for the range of growth temperatures explored in this work.

\section{ACKNOWLEDGMENTS}

This work has been supported by the Spanish MINECO through the projects TEC2015-66722-R and TEC2014-54260-C3-1-P, by the Comunidad de Madrid through the project MADRID-PV (S2013/MAE-2780) and by the European Commission through the LONGESST project (FP7 grant Agreement Number 607153). I. García is funded by the Spanish Programa Estatal de Promoción del Talento y su Empleabilidad through a Ramón y Cajal grant. E. Barrigón acknowledges financial support from European Union's Horizon 2020 research and innovation programme under the Marie Sklodowska - Curie grant agreement No 656208.

\section{REFERENCES}

[1] Friedman, D. J. Progress and challenges for next-generation high-efficiency multijunction solar cells. Current Opinion in Solid State and Materials Science 14(6): 131-138 (2010).

[2] H. Kroemer, "Polar-on-nonpolar epitaxy", Journal of Crystal Growth 81 (1-4) (1987) 193-204.

[3] E. Barrigón, S. Brückner, O. Supplie, H. Döscher, I. Rey-Stolle, T. Hannappel, "In situ study of Ge(100) surfaces with tertiarybutylphosphine supply in vapor phase epitaxy ambient”, J. Cryst. Growth (0). doi: 10.1016/j.jcrysgro.2012.07.046.

[4] E. Barrigón, B. Galiana, I. Rey-Stolle, "Reflectance anisotropy spectroscopy assessment of the MOVPE nucleation of GaInP on germanium (100)", Journal of Crystal Growth 315 (1, SI) (2011) 22-27, 15th 
International Conference on Metalorganic Vapor Phase Epitaxy (ICMOVPE-XV), Incline Village, NV, MAY 23-28, 2010. doi:\{10.1016/j.jcrysgro.2010.09.038\}.

[5] S. Brükner, O. Supplie, E. Barrigón, J. Luczak, P. Kleinschmidt, I. Rey-Stolle, H. Döscher, T. Hannappel, "In situ control of as dimer orientation on Ge(100) surfaces", Appl. Phys. Lett. 101 (12) (2012) 121602 $121602-4$.

[6] W. E. McMahon, J. M. Olson, “A scanning tunneling microscopy study of As/Ge(mnn) and p/Ge(mnn) surfaces", Journal of Crystal Growth 225 (2-4) (2001) 410 - 414.

[7] V. Andreev, V. Khvostikov, N. Kalyuzhnyi, S. Titkov, O. Khvostikova, M. Shvarts, "Gaas/ge heterostructure photovoltaic cells fabricated by a combination of MOCVD and zinc diffusion techniques", Semiconductors 38 (3) (2004) 355-359. doi:10.1134/1.1682614.

[8] D. Friedman, J. Olson, "Analysis of Ge junctions for GaInP/GaAs/Ge three-junction solar cells", Progress in Photovoltaics 9 (3) (2001) 179-189.

[9] L. Jong Boong, K. In, K. Ho Ki, C. Byung-Doo, “Amphoteric behavior of germanium in $\operatorname{In}_{0.5} \mathrm{Ga}_{0.5} \mathrm{P}$ grown by liquid phase epitaxy”.Applied Physics Letters 62 (14) (1993) 1620.

[10] E. Welser, W. Guter, A. Wekkeli, F. Dimroth, "Memory effect of Ge in III-V semiconductors", Journal of Crystal Growth 310 (23) (2008) 4799 - 4802, The Fourteenth International conference on Metalorganic Vapor Phase Epitaxy.jcrysgro. 2008.08.037.

[11] I. Yoon, S. Han, H. Park, T. Kim, “Amphoteric behavior of Ge dopants in $\operatorname{In}_{0.5} \mathrm{Ga}_{0.5} \mathrm{P}$ epilayers grown on GaAs(100) substrates", Journal of Physics and Chemistry of Solids 62 (3) (2001) 607 - 611. doi:10.1016/ S0022-3697(00)00224-9.

[12] J. Oh, J. C. Campbell, "Thermal desorption of Ge native oxides and the loss of Ge from the surface", Journal of Electronic Materials 33 (4) (2004) 364-367. doi:10. 1007/s11664-004-0144-4.

[13] M. Bosi, G. Attolini, C. Ferrari, C. Frigeri, M. Calicchio, F. Rossi, K. Vad, A. Csik, Z. Zolnai, "Effect of temperature on the mutual diffusion of Ge/GaAs and GaAs/Ge", Journal of Crystal Growth 318 (1) (2011) 367 - 371. The 16th International Conference on Crystal Growth (ICCG16).The 14th International Conference on Vapor Growth and Epitaxy (ICVGE14).

[14] C. K. Chia, J. R. Dong, D. Z. Chi, A. Sridhara, A. S. W. Wong, M. Suryana, G. K. Dalapati, S. J. Chua, S. J. Lee, "Effects of AlAs interfacial layer on material and optical properties of GaAs/Ge(100) epitaxy"., Applied Physics Letters 92 (14) (2008) 141905.

[15] B. Galiana, I. Rey-Stolle, C. Algora, K. Volz, W. Stolz, "A GaAs metalorganic vapor phase epitaxy growth process to reduce Ge outdiffusion from the Ge substrate”, Applied Physics Letters 92 (15) (2008) 152102152102- 3. doi:10.1063/1.2901029. 
[16] S. P. Tobin, S. Vernon, C. Bajgar, V. Haven, L. Geoffroy, M. Sanfacon, D. Lillington, R. Hart Jr, K. Emery, R. Matson, "High effciency GaAs/Ge monolithic tandem solar cells", in: Conference Record of the Twentieth Photovoltaic Specialists Conference, IEEE, 1988, pp. 405-410.

[17] H-M.Wu, S-J Tsai, H-H.Lin. "Ge auto-doping and out-diffusion in InGaP grown Ge substrate and their effects on the ordering of InGaP”. Journal of Applied Physics 119, 115302 (2016).doi: 10.1063/1.4944322.

[18] E. Barrigón, B. Galiana and I. Rey-Stolle, "Reflectance anisotropy spectroscopy assessment of the MOVPE nucleation of GaInP on germanium (100)”. Journal of Crystal Growth, (2011). 315(1): 22-27.

[19] J.M Olson and W.E McMahon "Structure of Ge (100) surface for high efficiency photovoltaics applications". $2^{\text {nd }}$ world conference and exhibition on photovoltaic solar energy conversion, Vienna (Austria), 6-10 Jul 1998.

[20] W. E. McMahon and J. M. Olson "Atomic-resolution study of steps and ridges on arsine-exposed vicinal Ge (100)”. Phys. Rev. B 60, (1999) p. 2480-2487.

[21] S.R. Kurtz, J.M. Olson, A.E. Kibbler, K.A. Bertness, "Incorporation of Zinc in MOCVD growth of GaInP”, Journal of Crystal Growth, Vol 124, p: 463-469, (1992).

[22] M. E. Greiner and J. F. Gibbons. "Diffusion and electrical properties of silicon-doped gallium arsenide". J. Appl. Phys. 57, 5181 (1985).

[23] K. L. Schulte, A. W. Wood, R. C. Reedy, A. J. Ptak, N. T. Meyer, and T.F Kuech. "Heteroepitaxy of GaAs on $(001) \Rightarrow 6^{\circ} \mathrm{Ge}$ substrates at high growth rates by hydride vapor phase epitaxy”.J. Appl. Phys. 113, 174903 (2013). 